\title{
Embracement of the person with mental illness at an emergency hospital service: a qualitative research
}

\author{
Acolhimento da pessoa em sofrimento mental em serviço hospitalar de emergência: pesquisa qualitativa \\ Acogimiento de la persona em sufrimento mental en servicio de urgencia en hospital: investigación cualitativa
}

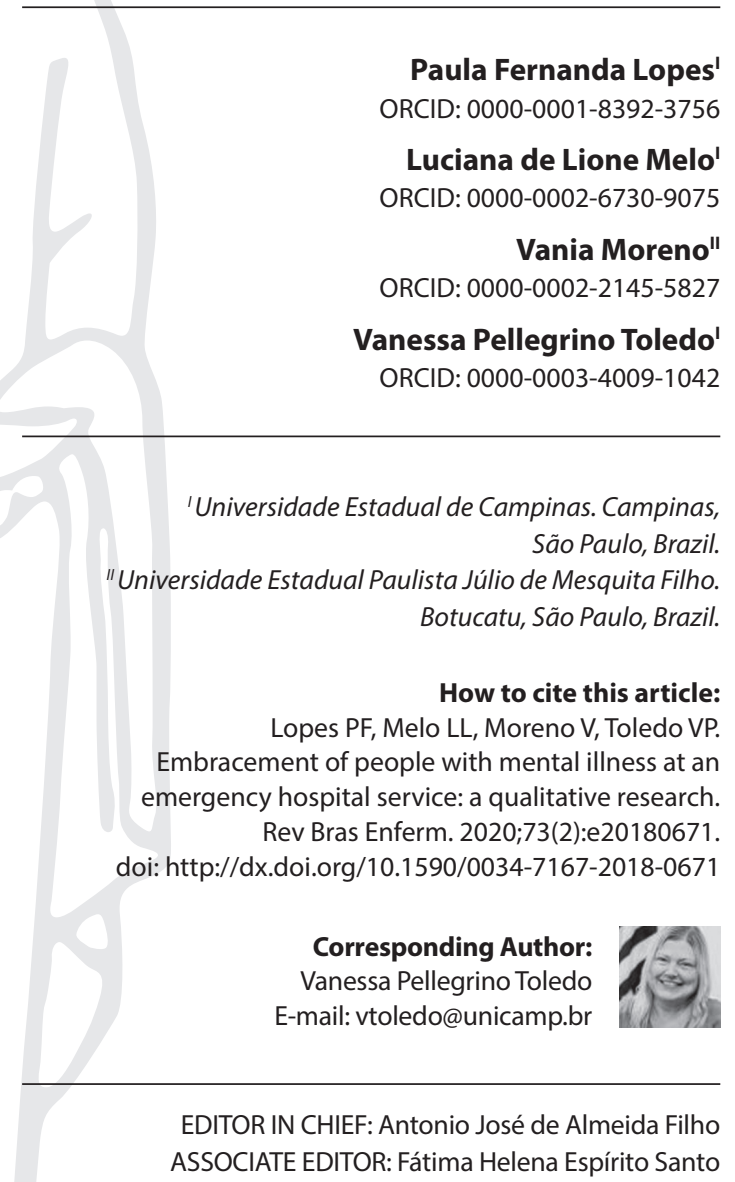

Submission: 09-03-2018 Approval: 06-17-2019

\begin{abstract}
Objectives: to understand actions of nurses who care for people person with mental illness at a Referenced Emergency Unit in a university hospital. Methods: a qualitative research based on Alfred Schütz's social phenomenology. Data collection was performed between December 2015 and January 2016 through phenomenological interviews with 13 nurses from an Emergency Unit. Results: nurses embrace according to their previous experiences. They easily identify biological complaints and, when they recognize psychiatric signs and symptoms, refer them to the psychiatrist. They raise doubts about what to do, so they expect to be qualified for such action, believing that a protocol could help as well as they need more time. Final considerations: the understanding of the lived type of nurse who embraces people with mental distress made possible in this study need recognition for research and interventions that focus on biological, psychic and social dimension articulation at embracement.

Descriptors: Nursing; User Embracement; Mental Health; Emergency Service, Hospital; Qualitative Research.
\end{abstract}

\section{RESUMO}

Objetivos: compreender a ação do enfermeiro que realiza acolhimento da pessoa em sofrimento mental em Unidade de Emergência Referenciada em um hospital universitário. Métodos: pesquisa qualitativa, fundamentada na fenomenologia social de Alfred Schütz. A coleta de dados foi realizada entre dezembro de 2015 ejaneiro de 2016, por meio de entrevistas fenomenológicas com 13 enfermeiros de uma Unidade de Emergência. Resultados: os enfermeiros acolhem de acordo com suas experiências prévias, identificam facilmente queixas biológicas e, quando reconhecem sinais e sintomas psiquiátricos, encaminham ao psiquiatra. Apresentam dúvidas sobre o que fazer, portanto, esperam ser qualificados para tal ação, acreditam que um protocolo poderia ajudar, bem como necessitam de mais tempo. Considerações finais: a compreensão do tipo vivido do enfermeiro que acolhe a pessoa em sofrimento mental possibilitou, neste estudo, o reconhecimento da necessidade de pesquisas e intervenções que foquem na articulação da dimensão biológica, psíquica e social na ação do acolhimento.

Descritores: Enfermagem; Acolhimento; Saúde Mental; Serviço Hospitalar de Emergência; Pesquisa Qualitativa.

\section{RESUMEN}

Objetivos: comprender las acciones de las enfermeras que reciben a la persona con enfermedad mental en una Unidad de Emergencia recomendada en un hospital universitario. Métodos: investigación cualitativa, basada en la fenomenología social de Alfred Schütz. La recolección de datos se realizó entre diciembre de 2015 y enero de 2016, a través de entrevistas fenomenológicas con 13 enfermeras de una Unidad de Emergencia. Resultados: las enfermeras aceptan de acuerdo con sus experiencias anteriores, identifican fácilmente las quejas biológicas y, cuando reconocen los signos y síntomas psiquiátricos, los remiten al psiquiatra. Tienen preguntas sobre qué hacer, por lo que esperan estar calificados para tal acción, creen que un protocolo podría ayudar y necesitar más tiempo. Consideraciones finales: la comprensión del tipo vivido de la enfermera que recibe a la persona en sufrimiento mental hizo posible en este estudio el reconocimiento de la necesidad de investigación e intervenciones que se centren en la articulación de la dimensión biológica, psíquica y social en lo acogimiento.

Descriptores: Enfermería; Acogimiento; Salud Mental; Servicio de Urgencia en Hospital; Investigación Cualitativa. 


\section{INTRODUCTION}

Emergency and urgency services have been presenting a change of scenery at a global level, witnessing an increase in patient demand, either with urgent complaints or with issues that can be resolved in Primary Care (PC) $)^{(1)}$. In Brazil, this problem is accentuated by the low resolvability in the primary health sector, which makes it difficult for patients to access the different levels of complexity. Moreover, emergency hospital services become the main entrance doors of the health system, being necessary to restructure access, so that all can be served, respecting universality, equity and comprehensiveness principles of the Brazilian Unified Health System (SUS - Sistema Único de Saúde) ${ }^{(1-2)}$. In this study, this service will be called Emergency Unit (EU), because it is a university hospital.

In order to manage patient flow, reduce queues and waiting time for access to health, risk classification embracement was implemented in the Brazilian National Humanization Policy (PNH - Política Nacional de Humanização), created by the Ministry of Health (MoH) in 2004. Nurses are responsible for assessing patients as soon as they arrive at the unit and identify care priority level, following a protocol of risk classification, according to the recommendation of $\mathrm{MoH}$, Ordinance 2048 of $2002^{(1-2)}$.

In Brazil, the Manchester Triage System (MTS) has been widely used in the public and private health system, establishing a risk classification in five categories that consider clinical history, signs and symptoms that lead to a flowchart composed of discriminators, in which positive or negative responses direct clinical priority and a defined color response time representing the increasing order of severity in blue, green, yellow, orange, and red. Care is organized so that patients who present signs of severity have priority in care ${ }^{(2-3)}$.

Although it is a sensitive and accurate tool for detecting those who need critical care, this classification system originally did not predict in their flowchart the access of mentally-ill people to the emergency service ${ }^{(3-5)}$.

People with mental illness daily seek EUs that are one of the Psychosocial Care Network (RAPS - Rede de Atenção Psicossocial) components in emergency and urgency sectors. RAPS, instituted in Brazil in 2011, is based on the imperative to offer care to users with distress or mental disorder and addictions arising from the use of crack, alcohol and other drugs. In addition to EUs, Primary Health Care, strategic psychosocial care, transitional residential care, hospital care, and psychosocial rehabilitation and institutionalization strategies are RAPS components ${ }^{(6)}$.

Although RAPS provides other care strategies to people with mental distress, demand for EU has been increasing ${ }^{(1,6)}$. This can be explained by the fact that these people, often because they feel isolated and afraid, are reluctant to seek specialized help until they feel in an emergency situation ${ }^{(7)}$. When patients seek help in Family Health Units, they are not always able to guarantee solvency of their problem, which can be explained by unavailability of network experts ${ }^{(8)}$. Thus, EU is an option for the patient to have his complaint heard by a health professional, which, in his conception, can solve his process of seeking care. Furthermore, it is important that the health professional establish a warm and human relationship to promote health care at the individual and collective levels, reducing access difficulty, which can be perceived when these patients arrive at the hospital and come across a professional unprepared to meet their demands $s^{(8-10)}$.

Regarding the $\mathrm{PNH}$, it is interesting to consider that embracement is not confined to risk classification. Embracement is proposed as an ethical stance, an action that must occur in all places and moments of the health service, approaching nursing care, considering that both involve the establishment of a relationship that aims to facilitate the bond between nurses and patient, based on comprehensive and humanized care ${ }^{(3,11)}$.

This study is justified by the problems faced at EUs, when they embrace people distress from mental illness, considering that they seek these units often due to the lack of PC and difficulty accessing health services ${ }^{(1-3)}$. Furthermore, this study aims to understand the possibilities of conducting user embracement distress from mental distress through the nurse's sharing of knowledge, taking for themselves the ethical responsibility for the demand resolution. This responsibility is often counteracted by the addition of a biomedical protocol to the host, in the triage format, which is exhausted at the embracement stage with selection of those who will be served by the service at the moment ${ }^{(2,4-5)}$. Thus, understanding extension is presented as a possible way to rethink and suggest new ways of performing this action and associate it with nursing care in the setting studied.

\section{OBJECTIVES}

To understand actions of nurses who care for the person distress from mental illness in a university hospital's REU.

\section{METHODS}

\section{Ethical aspects}

The study was approved by the Research Ethics Committee of Medical Sciences College of Universidade Estadual de Campinas, respecting Resolution 466/12 principles on research with human beings. Subjects who accepted to participate in this study granted their consent to the Free and Informed Consent Term. To ensure participants' anonymity, they were identified with the letter " $\mathrm{N}$ ", initial of the word "nurse", followed by Arabic numbers, according to the order in which the interviews were conducted.

\section{Theoretical-methodological framework and type of study}

Understanding that embracement is a qualified listening process, which is not limited to risk classification, and requires a relationship between nurse and patient to achieve their goals, qualitative research methodology was chosen, guided by the Consolidated Criteria for Reporting Qualitative Research (COREQ), supported by Alfred Schütz's social phenomenology $y^{(3,12-14)}$. The prerogative to choose the theoretical-methodological framework was based on embracement assumption that deals with the establishment of a relationship between nurse and patient, which can be explained by the concept of social interaction described by Schutz. This concept involves social action of at least two people who are oriented towards one another and thus live in complex networks of social relationships in their everyday world ${ }^{(12-13)}$. 


\section{Study setting}

The study was developed in a REU of a university hospital, located in the city of Campinas, São Paulo, Brazil. REU provide highly complex health services for the metropolitan area of the city, covering a population of approximately 5,000,000 inhabitants. Its main objective is to offer specialized treatment for cases of emergency and urgency, in which patients presenting the most serious conditions have priority of medical care ${ }^{(15)}$.

\section{Data source}

Study participants were 13 nurses who work at embracement room with REU's risk classification. Inclusion criteria were to be a nurse and to be present in the REU at the time of data collection. The exclusion criteria were to be nurses during vacation and leave in the period in which the data collection was performed.

\section{Collection and organization of data}

Obtaining experiential descriptions was accomplished by phenomenological interviews, which allowed the phenomenon description by the own subject who experience it ${ }^{(16)}$. Guiding questions for the interview were: tell me how you embrace the distress people at REU. How would you like it to be the achievement of this embracement?

The first question concerns previous experiences of the interviewee that justify how he performs embracement (reasons why). The second allows the interviewee to design possibilities that will come after the experience of receiving people with mental distress (reasons for) ${ }^{(12-13)}$.

Access to participants happened in their environment and working hours, by one of the researchers, after obtaining institution authorization. The purpose of this study was explained individually, and the invitation to participate was carried out. After acceptance, interviews were scheduled for the same day, respecting working hours.

The study was carried out from 2016 to 2018. Data collection was carried out from recorded interviews, with audio device and, later, transcribed. Recording was finished when the researcher's concerns were answered and the study goal was reached ${ }^{(17)}$.

\section{Data analysis}

Analysis of experiences reported by interviewees followed the following steps: reading and rereading each speech, aiming to identify the relevant aspects regarding the context of nurses' experience; identification and subsequent grouping of significant aspects of statements into units of meaning, that is, ideas that contain the sense of experience common to all subjects, which can be constituted by a word, a phrase or a behavior. Finally, units of meaning are synthesized to later compose the categories ${ }^{(18)}$.

The "reasons for" and "why" were identified in nurses' experiences, and grouped into categories that were discussed in the light of social phenomenology, using the concepts: social relation, everyday world, one-to-one relationship and natural behaviors ${ }^{(13,19)}$.

\section{RESULTS}

The speeches obtained from the "we" relationship built in the interviews, in an experience in which both the nurse and the interviewer experienced themselves in the situation, but also knew the experience of the situation by the other person, were organized into two groups: in the first, those that reflect their biographical trajectories, which refer to the stock of knowledge as a set of skills, recipes, models for carrying out the action of receiving people with mental distress in the REU, that is, the reasons why. And in the second, those that relate to the achievement of objectives, expectations, projects, what is idealized by them for the construction of an ideal embracement, that is, the reasons for ${ }^{(13,19)}$.

The "reasons why" were expressed in the category: nurse's action in receiving people with mental distress. The "reasons for" were highlighted in two categories: I hope to be qualified to embrace people with mental distress and I hope to have more time to embrace him.

\section{Nurse's action in receiving people with mental distress}

When questioned about receiving people with mental distress, nurses said that, most of the time, these people are not embraced by them. The patient decides for his care.

[...] the psychiatric patient arrives and he even directs embracement to make the file and he himself says that he wants to open the file for psychiatry. The embracement staff makes the record, discriminating that it is psychiatry, and leaves it in the home of psychiatry. The psychiatrist comes and calls the patient to care for. (N6)

Nurses only embrace people with physical or biological complaints. When receiving people with mental distress, it is performed by the psychiatrist.

[...] we do not, unless the complaint is clinical. If it is clinical, the first approach is ours. But the same psychiatric illness is usually done by them (psychiatrists) in the first care ... we'll perform care later. (N12)

Some nurses reported being able to identify psychiatric signs and symptoms during embracement, such as disconnected conversation, restlessness, suicidal ideation and hallucinations. However, the action resulting from this perception is to refer these people to the psychiatrist.

[...] patient came to the patient with the clinical complaint and during the classification of risk we understand that he needed an evaluation with psychiatry: disconnected conversation in the room shaking, crying, ideation, and a patient that we evaluate and come to a conclusion that needs go through psychiatry. (N4)

[...] when you have signs, signs of suicide, then I do not even go to the clinic [...] we start questioning the patient, and he says he hears voices... so if he has auditory hallucinations, if he has visual hallucinations, then lend up referring him to the psychiatrist. (N9)

Nurses mentioned that the psychiatrist is the team member most prepared to embrace people with mental distress, even though this preparation in their training. 
[...] no one more prepared than they (psychiatrists) to make the logical [...] embracement that we also have in training, but nothing like the psychiatrist. (N10)

Nurses who work at REU embracement said that they classify people with mental distress, often, because they have previous experiences of how care will be.

[...] a lot of things we end up sorting through the experience knowing that this situation is going to have a problem if you do not solve it soon. (N5)

\section{I hope to be qualified to embrace people with mental distress}

When questioned about their expectations for embracement of the mentally-ill person at REU, nurses responded that they would only be able to take action if they were trained to do so, as they do not currently feel prepared.

[...] I think people would need a preparation for this, even to broach right, and not everyone who has this training. (N2)

[...] I think we should have adequate training to approach these patients, which, today, I do not think there is. (N5)

Considering the lack of preparation, nurses hope that a protocol can help them, noting that welcoming people with mental distress is not simple. Counseling, guidance on signs and symptoms to be observed would support them, providing support for their actions. They said they have concerns about what to do at the first moment and how to understand what the person wants to say and then register correctly.

[...] we will have to have the training for this, because it is not part of our protocol, it does not cover psychiatry, nor orthopedics [...] perhaps psychiatry, we needed specific training. (N12)

[...] it needs a protocol for us to back up, specific, maybe, to them. The embracement is okay, we can do it, but the embracement of goal and the classification has to be together. Attending the psychiatric patient is a complex thing, even to register what he says is not common, it is not a clinical complaint "ouch, my foot hurts", it is not so. (N10)

Need to do a script. Something on which we can base ourselves just like we have. A protocol actually, that's the word I wanted to use. (N1)

\section{I hope to have more time to embrace him}

Nurses believe that time is essential to embrace people with mental distress; point to the need for a more cautious approach, since the person demands more attention and is often agitated and tearful.

[...] by the very specificity of the service, we would need more time for this type of service. It's a patient who demands more attention, more time for you to hear what he has to say. (N8)

[...] the approach is more cautious, the patient is often agitated, is tearful and demands a greater time. (N4)
They think that the psychiatrists have more time to make a more elaborate consultation, whereas the nurse would make an incomplete consultation with the few minutes that fit him, being unable to disentangle and listen properly.

[...] / think psychiatry staff have more time to make a more elaborate consultation. We are from the risk classification, who attends all patients, I think that sometimes it might be that an incomplete nursing consultation. (N6)

\section{DISCUSSION}

When nurses report that they do not usually embrace people with mental distress because they identify themselves at embracement as being from psychiatry and are referred to medical care, a biomedical logic is evident, in which a large part of emergency services have been development of everyday work focusing on the disease, and not the person and their needs, passing the problem on to another, rather than taking responsibility for their resolution ${ }^{(2)}$.

The same can be seen in a Canadian study on the experiences of mentally-ill or psychoactive substance abusers seeking an EU, in which participants report experiencing stigmatizing actions in which they are often seen as "just a psychiatric case"(7).

Risk classification fulfills well its role in an EU, as it allows more serious patients to be treated first. However, embracement should not be reduced only to the classification. It is necessary to increase the accountability of nurses in relation to patients and to increase the degrees of bonding and trust between them. Embracement expresses an approaching action, a "being with" and "close to", that is, an behavior of inclusion, of being in relation to something or someone ${ }^{(2-3)}$. Thus, development of the relationship with people with mental distress is interesting, considering that it is not the classification to measure the subjectivity of the person embraced since, as mentioned previously, there is no prediction in the flowchart about people with mental distress's dimension ${ }^{(3-5)}$.

It is at the moment of the one-to-one relationship that the other is directly perceived, in an act of social interaction, which enables the nurse to understand the patient as a person, guiding care for the "we" $(2,19)$. Such a concept can be applied by understanding embracement as an action that, in order to be developed, implies a one-to-one relationship between nurse and patient.

One-to-one relation shows its importance at the moment when situations also occur in which a person with mental distress cannot understand their symptoms so that they are declared to the receptionist. Thus, embracement nurses embrace this person and needs to develop the one-to-one relationship to identify their real demand ${ }^{(8,19)}$. However, not all interviewees feel empowered to identify psychiatric issues at first. Allegedly, the people who they embrace has only physical or biological demands.

As in other studies, it is evident collection of clinical information valorization from a biological perspective, by complaint interrogation, symptoms search and severity classification ${ }^{(9,20-21)}$. Nursing can still present a fragmented understanding of its work process, diverting from its focus, which is the implementation of the bond with the patient and the attendance of their health needs $s^{(3,10,22)}$. 
The nurse-patient relationship has happened mechanically and superficially, mainly in embracement rooms, summarizing its action following risk classification protocols, transforming the so subjective "embracement" in the objective "triage". This finding corroborates the findings of previous studies, in which action is understood by professionals as triage, transforming it into a bureaucratic and exclusionary process based on the format in which the patient files a complaint. From this, there is establishment of a conduct ${ }^{(7,21,23)}$. Thus, it does not seem possible to relate the existing embracement to comprehensiveness and universality principles of SUS.

Despite this, some of the nurses refer to being able to identify psychiatric signs and symptoms in the host, such as disconnected conversation, agitation, suicidal ideation, social isolation and hallucinations, which is a good sign. However, the conduct they take is to refer these people to the psychiatrist, who they think are the most appropriate professionals to serve them. The same is evidenced in studies on embracement of people in mental distress in the PC, where they are referred to Psychological Care Centers (Centros de Atenção Psicossocial) ${ }^{(8-10)}$.

Hence, it can be seen that the problem is not based on the lack of knowledge of nurses to identify psychiatric signs and symptoms, since their formation is predominantly biomedical, but rather on their difficulty in understanding the concept of embracement, as well as their care actions developed in their everyday world ${ }^{(8-11,24)}$. Embracement, in the $\mathrm{PNH}$, is not limited to isolated and punctual actions, such as the risk classification that is performed in a small room located at REU embracement. Embracement is not translated as a space or a place, but as an ethical stance that does not presuppose the specific hour or professional to do so. Embracement implies sharing knowledge, needs, possibilities, anguish and inventions. This is how we differentiate it from triage, since it is not constituted as a stage of the process, but as an action that must take place in all places and moments of the health service ${ }^{(2,9)}$.

According to the $\mathrm{PNH}$, humanized care is the premise of embracement, and is understood as actions of the health team that consider the needs of the physical and psychosocial care of the patient until the resolutive attention of their problems $s^{(2,8-9)}$.

Understanding people with mental distress as a human being who has a biography and who lives a particular moment of his life, it is important that the nurse understands the action of these people in the everyday world ${ }^{(19)}$. This understanding can occur from the identification of existential reasons, that is, issues that refer to lived experiences (reasons why) and also that refer to the goals that the person wants to achieve (reasons for) ${ }^{(19)}$. These reasons constitute the action of the subject in the everyday world that is permeated by a structure that makes possible social construction of subjects and influences their relations ${ }^{(19)}$. When all this process is established, from the one-to-one relationship between nurse and patient, there is the possibility of improving the understanding of this Being by nurses ${ }^{(13,19)}$.

Such improvement in understanding may favor nurses' empowerment regarding their relationship with the patient. However, some of the interviewees do not consider themselves the most prepared professionals to embrace people with mental distress and make decisions, passing the responsibility to physicians of the unit and complying with their orders, for care continuity ${ }^{(20)}$.

Despite the impediments imposed, nurses interviewed have other tools to be able to play their part in receiving people with mental distress. Some of the participants point out that although they do not have the necessary knowledge, they make use of their previous experiences with people with mental distress, their perceptions of the situation and common sense for decision-making.

These experiences are defined as natural behaviors, that is, an individual is guided in the situations of life precisely by the "experiences he has stocked" and by the "stock of knowledge he has in his hands". Therefore, nurses cannot interpret their observations, define the situation they are in, make plans, take actions, without first considering their stock of knowledge ${ }^{(13,19)}$.

Natural behaviors concept reinforces the results obtained in international studies which point out that nurses working at triage, a term used in the international setting, rely on their previous experiences to make decisions, since they did not embrace formal training to attend to people with mental distress $s^{(5,25-26)}$.

In some countries, such as Australia, Canada, and the United States, there are protocols that aim to aid in mental health triage, but the limitations appear when nurses encounter a person who does not speak or who speaks, but disorganized. Therefore, it is not possible to collect the information necessary to fit it into one of the categories. In these cases, they make decisions influenced by previous experiences and observations of their everyday world ${ }^{(5,19)}$.

When questioned about what they expect from the action of receiving people with mental distress, the need for more time to embrace them was emphasized. According to interviewees, person distress from mental illness demands more time, since it is necessary to "talk" with tranquility, it is often necessary to calm them and try to gain their trust in order to control the situation.

Patients who require a longer stay may break with the normal flow of EUs, since professionals working in this sector are focused on fast response to acute complaints. Care and management of these people who are in mental distress requires different abilities that focus on individuality. This can impact the team, whose specialty is to take care of physical emergencies, and can consequently lead to feelings of inadequacy, such as the speech of a nurse interviewed in an Australian study that says it is frustrating not to have time to attend them, since it is a run if the EU is busy ${ }^{(27)}$.

The hectic nature of the EUs may make it difficult for some nurses to establish one-to-one relationships with patients. Moreover, considering that the nurse-patient relationship is the basis for caring for the person distress from mental illness, it is understood that the little interaction with the patients, dictated by the time restriction, is not favorable to attend to the emotional needs required by people with mental distress ${ }^{(3,19,27)}$.

Nurses in this study also justify the need for training in bonding with the patient and for the correct approach to accepting the proposed behavior. Such findings corroborate the results of another study in which nurses believe that faculty mental health education provided them with only limited ability and confidence to apply knowledge in EU context ${ }^{(28)}$.

Literature has shown that nurses working in foster care or triage in EUs have admitted the lack of knowledge and confidence in care for people with mental distress ${ }^{(5,8,25-26)}$. Consequently, studies 
also point out that investment in the education of these nurses was successful in nursing practice, improving communication between the emergency and the mental health team. It also increased the confidence of nurses by accommodating people with mental distress and reducing intervention time. Such action can be identified as a possibility of work to be developed with the team studied, so that it can qualify embracement to people with mental distress at REU(29-30).

Just as in this study, where nurses recognize the need to know how to identify psychiatric signs and symptoms, an Australian study suggests that, with continuing education, nurses may have a better perception of the signs and symptoms of subtler psychosis or suicide be able to assess these patients in a more qualified manner. This suggestion is based on the results of the implementation of educational actions with nurses, considering that, before that, $50 \%$ of mentally-ill persons classified as nonurgent required further hospitalization. After the intervention, the number dropped to $20 \%$. Nurses felt more confident after being given mental health guidelines ${ }^{(29-31)}$.

Australians and Canadians have been working on mental health scales that are useful and relevant for the identification of psychiatric signs and symptoms at the time of embracement of nurses. This corroborates findings from this study, when nurses say protocols

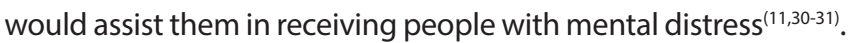

Although it is a standard tool, the insertion of a protocol in which it is possible to identify psychiatric signs and symptoms, could add improvements to embracement, as long as the nurse is able to understand the subjectivity of people with mental distress ${ }^{(11)}$.

This understanding allows nurses to recognize that before knowing how to identify signs and symptoms presented by a person distress from mental illness, it is important to know relational management techniques to approach it, not only by filling the checklist.

\section{Study limitations}

As a limitation of this study, it can be pointed out that data collection was performed in only one EU, so the results cannot be generalized. However, as generalization is not the central aspiration of qualitative research, the results of the study were not compromised, considering that the unit in question belongs to a public reference university hospital located in a metropolitan region.

\section{Contributions to Nursing, Health or Public Policy}

Embracement represents the first contact of patients with the multidisciplinary team, since such action does not presuppose a specific professional to do so. However, the nurse who acts in embracement through the risk classification is responsible for this first contact, precisely due to its position in institution embracement and its attribution to identify the priority levels of care of those who seek the service ${ }^{(2,8)}$.

In the case of an EU, it should be considered that the classification of risk in a short time is a requirement. Likewise, the longer time to embrace people with mental distress in crisis is also a requirement. This study then presents as a possibility to solve these problems, to equate one-to-one relationship, nursing care and the Manchester protocol, nursing process implementation through nursing consultation ${ }^{(32-33)}$.

One possibility of advancement in relation to the subject studied, to make feasible this proposal of the nursing process in embracement, is that the nursing consultation can be supported by a protocol in the form of a checklist. Thus, nurses make decisions with agility, but without compromising the essence of embracement, as a moment of establishing a one-to-one relationship with people with mental distress ${ }^{(8,31,33)}$. A contribution of this study is to recognize that the nurse, before being able to identify the signs and symptoms presented by a person with mental distress, needs to know relational management techniques to approach it, not reducing only to checklist fulfillment.

Embracement empowerment to the mentally-ill person by the nurse can serve as an important tool for the EU team work, since it is in the dialogical perspective that possibilities of effective action in care for people with mental distress ${ }^{(18,31-33)}$.

\section{FINAL CONSIDERATIONS}

The theoretical-methodological approach of Alfred Schütz's social phenomenology contributed to the understanding of how the nurse performs embracement of people with mental distress at REU.

Such understanding favored outlining of the lived type of nurse who often does not embrace people with mental distress due to institutional issues, and that when he does, his action is based on the biomedical model, perpetuating the image of a subordinate professional, not recognizing embracement as a nursing action. Thus, it stagnates in the referral conduct of these patients for medical evaluation.

It was possible to understand that nurses expect to have more time to embrace people with mental distress, a fact that is emphasized in the foreign literature. Nurses still believe that such an embracement could only happen if they were trained for action, which is widely studied in countries such as Australia and Canada, reporting great care improvements for these patients and also raising the confidence levels of professionals. Considering the setting presented as a diagnosis of the lived type of nurse who embraces people with mental distress, this study opens possibilities for interventions and new researches.

\section{REFERENCES}

1. Guedes HM, Almeida AGP, Ferreira FO, Vieira Jr G, Chianca TCM. Classificação de risco: retrato de população atendida num serviço de urgência brasileiro. Rev Enf Ref. 2014; serIV(1):37-44. doi: 10.12707/RIII13108

2. Ministério da Saúde (BR). Secretaria de atenção à saúde. Política Nacional de Humanização da Atenção e Gestão do SUS. Acolhimento e classificação de risco nos serviços de urgência [Internet]. Brasília: Ministério da Saúde; 2009 [cited 2017 Apr 22]. Available from: http:// 
bvsms.saude.gov.br/bvs/publicacoes/acolhimento_classificaao_risco_servico_urgencia.pdf

3. Guedes MVC, Henriques ACPT, Lima MMN. Acolhimento em um serviço de emergência: percepção dos usuários. Rev Bras Enferm. 2013;66(1):31-7. 10.1590/S0034-71672013000100005

4. Oliveira JLC, Gatti AP, Barreto MS, Bellucci Jr JA, Góes HLF, Matsuda LM. User embracement with risk classification: perceptions of the service users of an emergency care unit. Texto Contexto Enferm. 2017;26(1):e0960014. doi: 10.1590/0104-07072017000960014

5. Brown $A M$, Clarke DE. Reducing uncertainty in triaging mental health presentations: examining triage decision-making. Int Emerg Nurs. 2014;22(1):47-51. doi: 10.1016/j.ienj.2013.01.005

6. Nobrega MPSS, Domingos AM, Silveira ASA, Santos JC. Weaving the West Psychosocial Care Network of the municipality of São Paulo. Rev Bras Enferm. 2017;70(5):965-72. doi: 10.1590/0034-7167-2016-0566

7. Wise-Harris D, Pauly D, Kahan D, Bibiana JT, Hwang SW, Stergiopoulos V. “Hospital Was the Only Option”: experiences of frequent emergency department users in mental health. Adm Policy Ment Health. 2016;44(3):405-12. doi: 10.1007/s10488-016-0728-3

8. Sucigan DHI, Toledo VP, Garcia APRF. Acolhimento e saúde mental: desafio profissional na estratégia saúde da família. Rev Rene [Internet]. 2012 [cited 2017 Apr 20];13(1):2-10. Available from: http://www.periodicos.ufc.br/rene/article/view/3756

9. Fontão MC, Rodrigues J, Lino MM, Lino MM, Kempfer SS. Cuidado de enfermagem às pessoas atendidas na emergência por tentativa de suicídio. Rev Bras Enferm. 2018;71(Suppl 5):2199-205. doi: 10.1590/0034-7167-2017-0219

10. Rigotti DG, Garcia APRF, Silva NG, Mitsunaga TM, Toledo VP. Acolhimento de usuários de drogas em Unidade Básica de Saúde. Rev Rene. 2016;17(3):346-55. doi: 10.15253/2175-6783.2016000300007

11. Oliveira RM, Siqueira Jr AC, Furegato ARF. Perceptions on psychiatric nursing care at a general hospital inpatient unit. Acta Sci, Health Sci. 2016;38(1):39-47. doi: 10.4025/actascihealthsci.v38i1.28673

12. Jesus MCP, Capalbo C, Merighi MAB, Oliveira DM, Tocantins FR, Rodrigues BMRD, et al. The social phenomenology of Alfred Schütz and its contribution for the nursing. Rev Esc Enferm USP. 2013;47(3):736-41. doi: 10.1590/S0080-623420130000300030

13. Wagner HTR. Sobre fenomenologia e relações sociais: Alfred Schütz. Petrópolis: Vozes; 2012.

14. Padilha VM, Schettini CSS, Santos Jr A, Azevedo RCS. Profile of patients attended as psychiatric emergencies. Sao Paulo Med J. 2013;131(6):398404. doi: 10.1590/1516-3180.2013.1316598

15. Carvalho AS. Metodologia da entrevista: uma abordagem fenomenológica. 2a ed. Rio de Janeiro: Agir; 1991.

16. Nascimento LCN, Souza TV, Oliveira ICS, Moraes JRMM, Aguiar RCB, Silva LF. Theoretical saturation in qualitative research: an experience report in interview with schoolchildren. Rev Bras Enferm. 2018;71(1):228-33. doi: 10.1590/0034-7167-2016-0616

17. Martins J, Bicudo MAV. A pesquisa qualitativa em psicologia: fundamentos e recursos básicos. 5a ed. São Paulo: Centauro; 2005.

18. Schütz A. Fenomenologia del mundo social. Buenos Aires: Paidós; 1973.

19. Salvador PTCO, Alves KYA, Martins CCF, Santos VEP, Tourinho FSV. Motivos para o empoderamento da enfermagem: reflexões à luz de Alfred Schütz. Rev Min Enferm [Internet]. 2013 [cited 2017 Apr 28];17(4):1014-9. Available from: http://www.reme.org.br/artigo/detalhes/902

20. Costa PCP, Garcia APRF, Toledo VP. Welcoming and nursing care: a phenomenological study. Texto Contexto Enferm. 2016;25(1):e4550015. doi: 10.1590/0104-07072016004550014

21. Costa MAR, Versa GLGS, Bellucci JJA, Inoue KC, Sales CA, Matsuda LM. Admittance of risk-classified cases: assessment of hospital emergency services. Esc Anna Nery. 2015;19(3):491-7. doi: 10.5935/1414-8145.20150065

22. Gonçalves AVF, Bierhals CCK, Paskulin LMG. Embracement with risk classification in the emergency department from the perspective of older adults. Rev Gaúcha Enferm. 2015;36(3):14-20. doi: 10.1590/1983-1447.2015.03.52422

23. Padovani O, Corrêa AK. Currículo e formação do enfermeiro: desafios das universidades na atualidade. Sau Transf Soc [Internet]. 2017 [cited 2017 Apr 15];8(2):112-9. Available from: http://incubadora.periodicos.ufsc.br/index.php/saudeetransformacao/article/view/3841/4990

24. Clarke DE, Boyce-Gaudreau K, Sanderson A, Baker JA. ED triage decision making with mental health presentations: a "think aloud" study. J Emerg Nurs. 2015;41(6):496-502. doi: 10.1016/j.jen.2015.04.016

25. Downey, LVA, Zun LS, Burke T. Comparison of Canadian triage acuity scale to Australian Emergency Mental Health Scale triage system for psychiatric patients. Int Emerg Nurs. 2015;23(2):138-43. doi: 10.1016/j.ienj.2014.06.006

26. Alakeson V, Pande N, Ludwig M. A plan to reduce emergency room 'boarding' of psychiatric patients. Health Aff (Millwood). 2010;29(9):163742. doi: $10.1377 /$ hlthaff.2009.0336

27. Kerrison AS, Chapman R. What general emergency nurses want to know about mental health patients presenting to their emergency departments. Accid Emerg Nurs. 2007;15(1):48-55. doi: 10.1016/j.aaen.2006.09.003

28. Pessoa Jr JM, Santos RCA, Clementino FS, Nascimento EGC, Miranda FAN. Mental health education and professional practice in the psychiatric hospital. Texto Contexto Enferm. 2016;25(3):e3020015. doi: 10.1590/0104-07072016003020015

29. Mannocci A, Meggiolaro A, Feller E, La Torre G, Guzzo AS. Knowledge of Emergency Department Triage nurses in management of patients with mental health needs: comparisons with the Triage Model of Lazio (TLM). Clin Ter. 2015;166(3):121-30. doi: 10.7417/CT.2015.1842

30. Broadbent M, Moxham L, Dwyer T. Implications of the emergency department triage environment on triage practice for clients with a mental illness at triage in an Australian context. Australas Emerg Nurs J. 2014;17(1):23-9. doi: 10.1016/j.aenj.2013.11.002 
31. Camatta MW, Schneider JF. A Psychosocial Care Center Team's work from a family perspective. Rev Esc Enferm USP. 2009;43(2):393-400. doi: $10.1590 /$ S0080-62342009000200019

32. Schütz A. El problema de la realidad social. Buenos Aires: Amorrortu; 2003.

33. Lopes PF, Garcia APRF, Toledo VP. Processo de Enfermagem no cotidiano do enfermeiro nos Centros de Atenção Psicossocial. Rev Rene. 2014;15(5):780-8. doi: 10.15253/2175-6783.2014000500007 